\title{
Identification of Potential Citrate Metabolism Pathways in Carnobacterium maltaromaticum
}

\author{
Heng Li ${ }^{1,2}$, Nancy E. Ramia ${ }^{3}$, Frédéric Borges ${ }^{3}$, Anne-Marie Revol-Junelles ${ }^{3}$, Finn Kvist Vogensen ${ }^{4}$ \\ and Jørgen J. Leisner $2, * \mathbb{D}$ \\ 1 Pasteurien College, Soochow University, Suzhou 215123, China; hli@suda.edu.cn \\ 2 Department of Veterinary and Animal Sciences, Faculty of Health and Medical Sciences, \\ University of Copenhagen, DK-1870 Frederiksberg, Denmark \\ 3 Laboratoire d'Ingénierie des Biomolécules (LIBio), Ecole Nationale Supérieure d'Agronomie et des Industries \\ Alimentaires (ENSAIA), Université de Lorraine, LIBio, F-54000 Nancy, France; \\ ramia.nancy@gmail.com (N.E.R.); frederic.borges@univ-lorraine.fr (F.B.); \\ anne-marie.revol@uni-lorraine.fr (A.-M.R.-J.) \\ 4 Department of Food Science, Faculty of Science, University of Copenhagen, \\ DK-1958 Frederiksberg, Denmark; fkv@food.ku.dk \\ * Correspondence: jj@@sund.ku.dk
}

Citation: Li, H.; Ramia, N.E.; Borges, F.; Revol-Junelles, A.-M.; Vogensen, F.K.; Leisner, J.J. Identification of Potential Citrate Metabolism Pathways in Carnobacterium maltaromaticum. Microorganisms 2021, 9, 2169. https://doi.org/10.3390/ microorganisms 9102169

Academic Editor: Franca Rossi

Received: 25 September 2021

Accepted: 15 October 2021

Published: 18 October 2021

Publisher's Note: MDPI stays neutral with regard to jurisdictional claims in published maps and institutional affiliations.

Copyright: (c) 2021 by the authors. Licensee MDPI, Basel, Switzerland. This article is an open access article distributed under the terms and conditions of the Creative Commons Attribution (CC BY) license (https:// creativecommons.org/licenses/by/ $4.0 /)$.

\begin{abstract}
In the present study, we describe the identification of potential citrate metabolism pathways for the lactic acid bacterium (LAB) Carnobacterium maltaromaticum. A phenotypic assay indicated that four of six C. maltaromaticum strains showed weak (Cm 6-1 and ATCC 35586) or even delayed (Cm 3-1 and $\mathrm{Cm} 5-1$ ) citrate utilization activity. The remaining two strains, $\mathrm{Cm}$ 4-1 and $\mathrm{Cm} \mathrm{1-2} \mathrm{gave} \mathrm{negative}$ results. Additional analysis showed no or very limited utilization of citrate in media containing $1 \%$ glucose and 22 or $30 \mathrm{mM}$ citrate and inoculated with $\mathrm{Cm} \mathrm{6-1} \mathrm{or} \mathrm{ATCC} \mathrm{35586.} \mathrm{Two} \mathrm{potential}$ pathways of citrate metabolism were identified by bioinformatics analyses in C. maltaromaticum including either oxaloacetate (pathway 1) or tricarboxylic compounds such as isocitrate and $\alpha$ ketoglutarate (pathway 2) as intermediates. Genes encoding pathway 1 were present in two out of six strains while pathway 2 included genes present in all six strains. The two potential citrate metabolism pathways in C. maltaromaticum may potentially affect the sensory profiles of milk and soft cheeses subjected to growth with this species.
\end{abstract}

Keywords: lactic acid bacteria; cheese; citric acid; oxaloacetate; diacetyl

\section{Introduction}

The main metabolic activity of lactic acid bacteria (LAB) in milk fermentation is lactic acid production. Various species and strains of LAB, including Carnobacterium maltaromaticum isolated from Mozzarella cheese, are also able to metabolize citrate, which leads to the production of aroma compounds [1-4] . C. maltaromaticum is common in milk and soft cheeses as well as in meat and fish products. It is also isolated from a range of cold and temperate environments. Some strains of $C$. maltaromaticum (previously named Carnobacterium piscicola) are fish pathogens [5-8].

The presence of $C$. maltaromaticum in milk and soft cheeses may affect the sensory profiles of such products [9]. In this context, citrate is of interest as LAB produces flavor compounds from this compound, including acetate, diacetyl, acetoin, and 2,3-butanediol [1,3,4,10-12].

To extend our knowledge on potential citrate metabolism pathways in C. maltaromaticum, we here compare phenotypic tests for citrate metabolism with analysis of wholegenome sequences to identify genes predicted to be involved in citrate metabolism. The main aim was to supply information on the potential sensory applicability of using $C$. maltaromaticum as adjunct cultures in soft cheeses. 


\section{Materials and Methods}

\subsection{Strains Collection, Phenotypic Tests, and Bioinformatic Analyses}

Table 1 lists $C$. maltaromaticum strains used in phenotypic tests and bioinformatics and their sources.

Table 1. Overview of phenotypical and bioinformatical analyses for selected strains of Carnobacterium maltaromaticum.

\begin{tabular}{|c|c|c|c|c|c|}
\hline \multirow[b]{2}{*}{ Strain } & \multirow[b]{2}{*}{ Isolated from } & \multirow{2}{*}{ Citrate Metabolic Phenotype ${ }^{a}$} & \multicolumn{2}{|c|}{ Genes Encoding Specific Pathway } & \multirow[b]{2}{*}{ Ref. } \\
\hline & & & Pathway $1^{b}$ & Pathway $2^{c}$ & \\
\hline $\mathrm{Cm} \mathrm{4-1} 1^{\mathrm{d}}$ & Sphagnum pond & - & + & + & [13] \\
\hline Cm 6-1 & Sphagnum pond & $(+)$ & + & + & [13] \\
\hline Cm 1-2 & Sphagnum pond & - & - & + & {$[13]$} \\
\hline Cm 3-1 & Sphagnum pond & $(+)(\mathrm{d})$ & - & + & [13] \\
\hline Cm 5-1 & Sphagnum pond & $(+)(d)$ & - & + & [13] \\
\hline ATCC 35586 & Diseased salmon & $(+)$ & - & + & [6] \\
\hline
\end{tabular}

${ }^{a}$ indicates a negative phenotype, $(+)$ indicates a weak positive phenotype, $(d)=$ delayed reaction. ${ }^{b}$ See Figure $1 \mathrm{~B}$ and Table S1 for a list of genes. ${ }^{c}$ See Figure 2B and Table S1 for a list of genes. ${ }^{d}$ Numbers for Sphagnum pond isolates as given in Leisner et al. [13]. The first number indicates in each case a specific rep-PCR cluster.

\subsection{Phenotypic Tests for Citrate Metabolism and Test for Growth on a Citrate-Containing Medium}

An agar medium for the detection of citrate utilizing LAB was modified from the procedure described by Kempler and McKay [14]. The basal medium contained 0.25\% milk protein hydrolysate peptone (Bacto, Mt Pritchard, Australia) and 1.5\% agar, autoclaved at $121{ }^{\circ} \mathrm{C}$ for $15 \mathrm{~min}$, after which sterile $0.4 \%$ nonfat milk (Arla Foods, Aarhus, Denmark) and $0.5 \% \mathrm{w} / \mathrm{v}$ glucose were added, and $\mathrm{pH}$ was adjusted to 6.6. Finally, two solutions, one containing $10 \%$ potassium ferricyanide and one containing $1 \mathrm{~g}$ ferric citrate and $1 \mathrm{~g}$ sodium citrate in $40 \mathrm{~mL}$ water, were heat-treated at $100{ }^{\circ} \mathrm{C}$ for $30 \mathrm{~min}$ and $10 \mathrm{~mL}$ of each solution was added to $1 \mathrm{~L}$ agar medium. Plates were dried in the dark overnight at $30{ }^{\circ} \mathrm{C}$ and bacterial cultures were streaked, either directly from frozen culture vials or an overnight culture propagated in All Purpose Tween broth (APT) (Difco, Sparks, MD, USA). Incubation was performed under aerobic or microaerophilic conditions (plates were incubated in a jar with air exhausted by a tea light) in the dark at $25^{\circ} \mathrm{C}$. Cultures were scored positive if they developed a blue color after 3 or 5 days.

A determination of citrate metabolism by chemical analysis was carried out by subculturing the Cm 6-1 and ATCC 35586 strains in APT broth (Difco, Beckton, Dickinson and Company, Sparks, MD, USA) with 1\% glucose and 22 or $30 \mathrm{mM}$ citrate. Strains were sub-cultured twice o/n in APT broth at $25^{\circ} \mathrm{C}$ before adding $10 \mu \mathrm{l}$ of $22 \mathrm{~h}$ cultures to $10 \mathrm{~mL}$ of APT broth. The cultures were incubated anaerobically (Anaerogen, Oxoid, Basingstoke, UK) for 9 days at $25^{\circ} \mathrm{C}$ before sampling. Viable counts were determined by the transfer of appropriate dilutions of sterile peptone saline to APT agar plates that were incubated for three days anaerobically at $25^{\circ} \mathrm{C}$ before enumeration. Citric acid was determined by MS-Omics (Vedbæk, Denmark) using a gas chromatography-mass spectrometry (GC-MS) method. Samples were derivatized as described by Smart et al. [15] and the derivatization reaction was stopped by the addition of chloroform. Subsequently, the chloroform phase with derivatives was injected into the GC. All samples were analyzed in a randomized order. Analysis was performed using gas chromatography (7890B, Agilent, Santa Clara, CA, USA) coupled with a quadrupole mass spectrometry detector (5977B, Agilent). The system was controlled by ChemStation (Agilent). Raw data were converted to netCDF format using Chemstation. Then, the data were imported and processed in MATLAB R2018b (Mathworks, Inc., Natick, MA, USA) using the PARADISe software described by Johnsen et al. [16].

Sample analysis for contents of short-chain fatty acids was carried out by MS-Omics as follows. Samples were acidified using hydrochloride acid, and deuterium-labeled internal standards were added. All samples were analyzed in a randomized order. Analysis was performed using a high polarity column (Zebron ${ }^{\mathrm{TM}}$ ZB-FFAP, GC Cap. Column 
$30 \mathrm{~m} \times 0.25 \mathrm{~mm} \times 0.25 \mu \mathrm{m}$ ) installed in a GC coupled with a quadropole detector and controlled by ChemStation, similar to the analysis for citric acid. Raw data was converted to netCDF format using Chemstation before the data was imported and processed in Matlab R2014b (Mathworks, Inc.) using the PARADISe software [16].

\subsection{Whole-Genome Sequencing}

Isolates were grown on APT agar for $24 \mathrm{~h}$ at $30^{\circ} \mathrm{C}$ and genomic DNA was extracted and purified using the DNeasy Blood \& Tissue Kit, according to the manufacturer's instructions (Qiagen $\mathrm{GmbH}$, Hilden, Germany). The quality of the extracted DNA was assessed using a Nanodrop ND-1000 spectrophotometer (Nanodrop Technologies, Wilmington, DE, USA) and electrophoresis on a $1.0 \%(w / v)$ agarose gel. Sequencing was performed using MiSeq (Illumina) at a $300 \mathrm{bp}$ paired-end read format. Sequencing reads were de novo assembled with CLC Genomics Workbench 10.1.1 (Qiagen, Aarhus, Denmark).

\subsection{Bioinformatic Analyses for Genome Annotation}

The presence of genes included in citrate metabolism pathways 1 and 2 were examined for a number of Carnobacterium spp. whole-genome sequences. A single nucleotide polymorphism (SNP) cladogram was constructed using Carnobacterium spp. sequences downloaded from NCBI GenBank $(n=21)$, RAST annotation server $(n=1)$, and the C. maltaromaticum isolates from the present study $(\mathrm{n}=6)$. The annotations of the pathways were predicted via the RAST annotation server [17-19]. The SNP tree was constructed by CSI Phylogeny 1.4 (https:/ / cge.cbs.dtu.dk, accessed on 17 June 2021) with ATCC 35586 as the reference genome. The select minimum depth at SNP positions was set at 10x. The select minimum relative depth at SNP positions was $10 \%$. The select minimum distance between SNPs (prune) was $10 \mathrm{bp}$, while the select minimum SNP quality was 30 . Finally, the select minimum read mapping quality was 25 and the select minimum Z-score was set at 1.96 . Then, the phylogenetic tree was imported to iTOL (Interactive Tree of Life) for visualization (https: / /itol.embl.de, accessed on 17 June 2021) [20]. Leaf sorting was set as the default and the tree was re-rooted at midpoint with ATCC 35586 as the reference genome.

Detailed genome annotations were carried out using a combined bioinformatical approach including the RAST annotation server [17-19], SMART [21], Pfam 32.0 [22], Uniprot database [23], KEGG database [24], and local Blast within the CLC Genomics Workbench 10.1.1. Briefly, whole-genome assemblies were uploaded to the seed-based RAST annotation server for genome annotation and in MicroScope [25]. To improve the annotation accuracy for genes found to be associated with citrate metabolism, based on the KEGG pathway website, sequence alignments for specific genes were downloaded from the Pfam and Uniprot databases. The hits with an e-score of $1 \mathrm{e}^{-20}$ or lower were considered as indicative of putative functional proteins or enzymes [6].

Moreover, the contigs containing the cit operon were retrieved from the wholegenome sequence and blasted against all the strains. The results were visualized in GView (Figures 1 and 2 ) [26]. The presence of transmembrane helices was predicted by using the TMHMM server [27] at DTU Bioinformatics at the Department of Bio and Health Informatics of the Technical University of Denmark. Protein domain predictions were obtained from SMART (http:/ / smart.embl-heidelberg.de, accessed on 17 June 2021). Figures 1 and 2 list the annotated gene products encoding the functions of citrate uptake or citrate metabolism with oxaloacetate as an intermediate (pathway 1) or the truncated TCA cycle (pathway 2). 


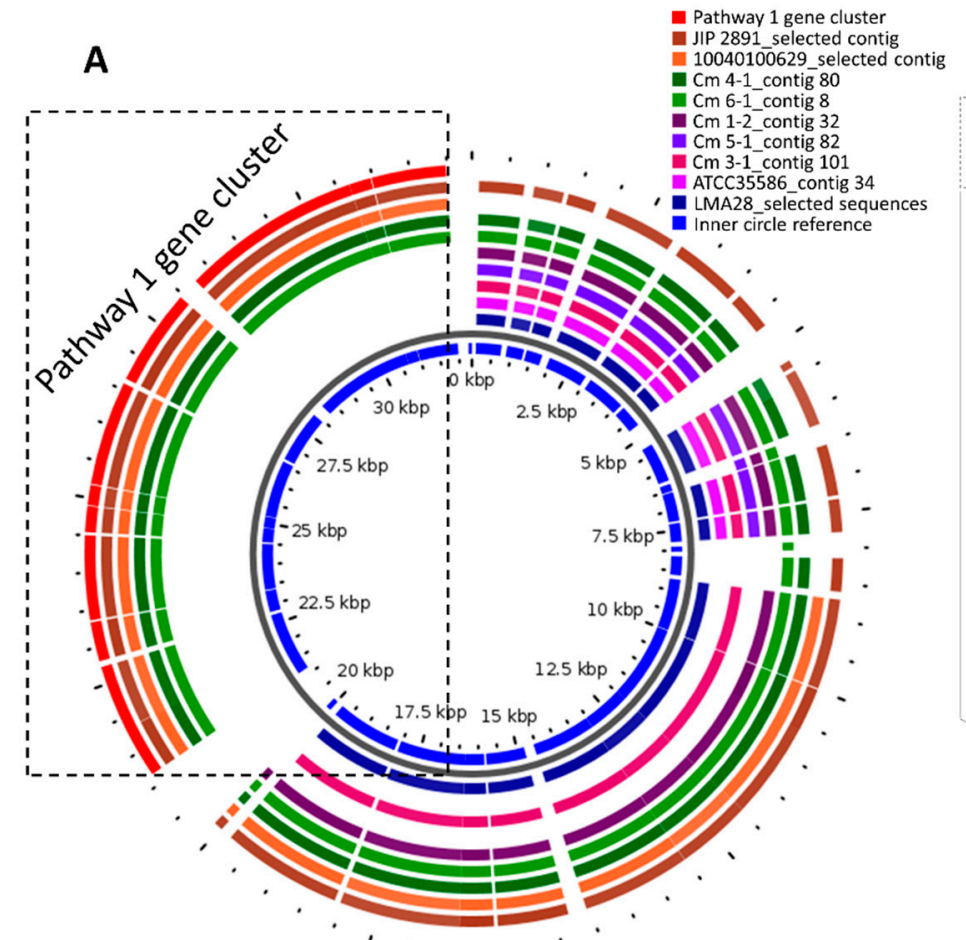

3134: Hypothetical protein; Transcriptional regulator, GntR family

3135: Hypothetical protein; CitG;

triphosphoribosyl-dephospho-CoA synthases

3136: Hypothetical protein; CitT(CitX); an acyl carrier protein 3137: Oxaloacetate
decarboxylase beta ch 3138: Hypothetical protein; biotin/lipoyl attachment domain

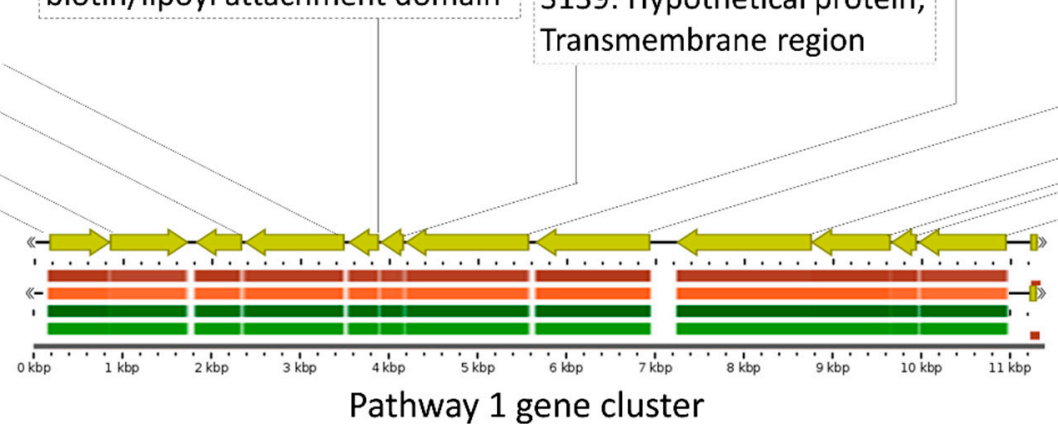

Figure 1. (A) Comparison of strains with contigs including genes encoding pathway 1. For comparison, whole-genome sequences of three strains included in the initial Single Nucleotide Polymorphism analysis (SNP) (Figure S1) were added: JIP 2891 and 10040100629 are sequences for isolates from an adult, diseased pike, and LMA28 is a sequence of an isolate from soft, ripened cheese. (B) Example of the genes predicted to be included in pathway 1 in the C. maltaromaticum $\mathrm{Cm}$ 6-1 strain. 


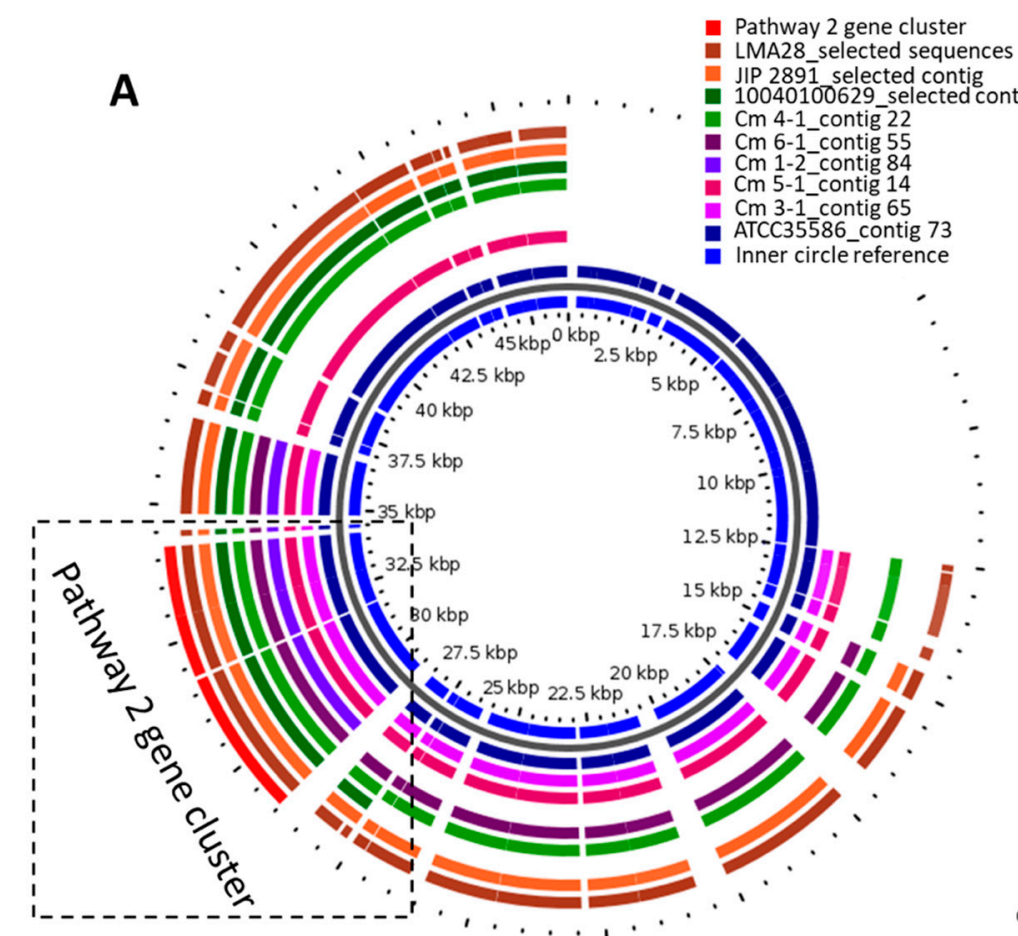

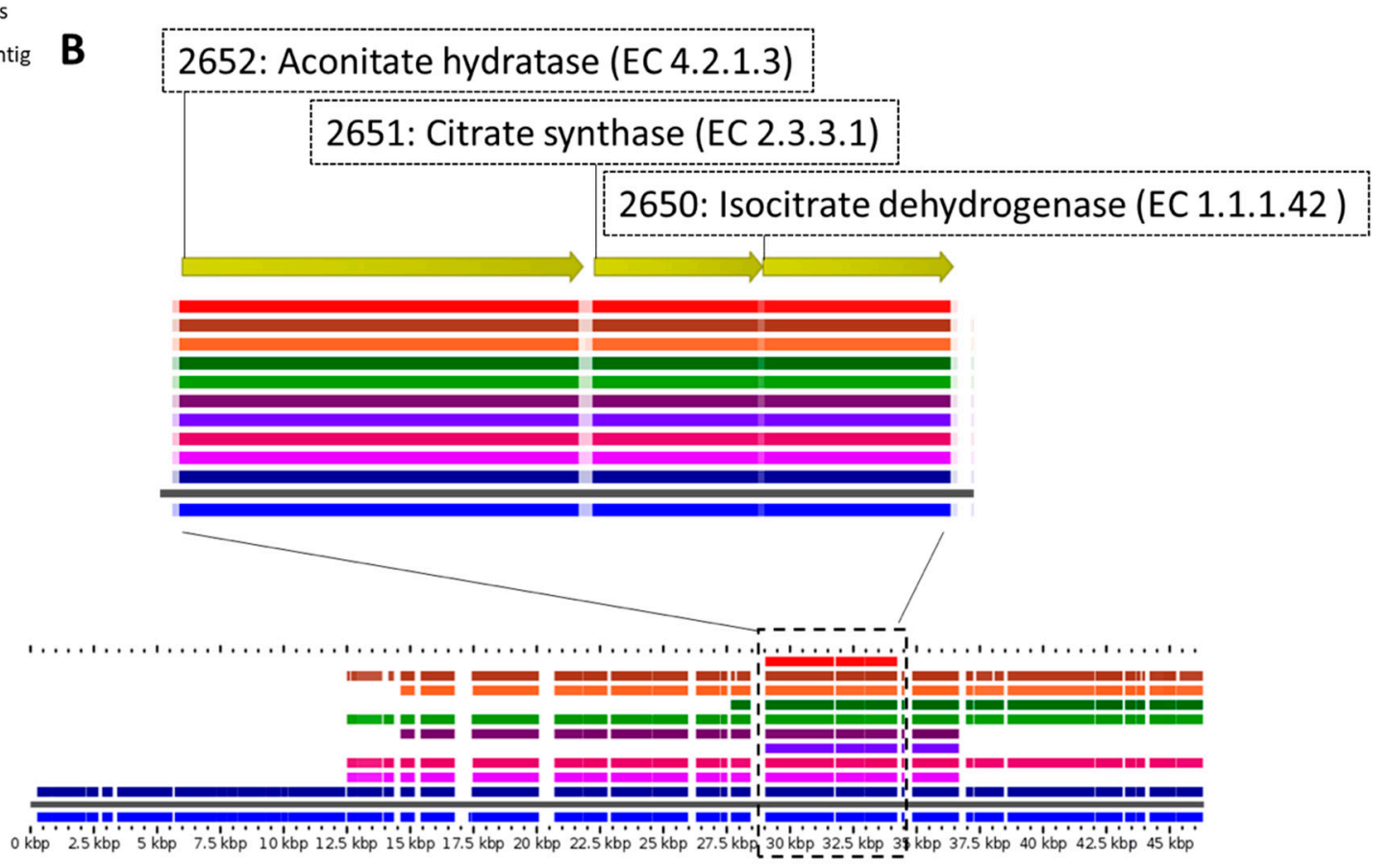

Pathway 2 gene cluster

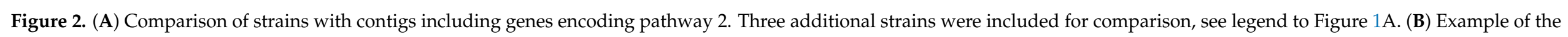
genes predicted to be included in pathway 2 in the C. maltaromaticum $\mathrm{Cm}$ 6-1 strain. 


\section{Results and Discussion}

C. maltaromaticum citrate metabolism was tested on a citrate-containing agar medium $[2,14]$. The positive controls, Enterococcus faecalis ATCC 29212, Lactiplantibacillus pentosus DSMZ 20314, and Lactiplantibacillus plantarum LMG 11405, all showed strong activity, whereas Pediococcus acidilactici PAH and Lactococcus lactis ATTC 11454 showed no activity, which was also the case for Carnobacterium gallinarum LMG 9841 and Carnobacterium divergens LMG 9199. Four C. maltaromaticum strains (Cm 6-1, Cm 3-1, Cm 5-1, and ATCC 35586) showed weak activity, among which the $\mathrm{Cm}$ 3-1 and $\mathrm{Cm}$ 5-1 strains had delayed positive phenotypes during aerobic incubation at $25^{\circ} \mathrm{C}$ (Table 1). The remaining strains, $\mathrm{Cm} 4-1$ and $\mathrm{Cm} 1-2$, gave negative results under these conditions. Incubation under microaerophilic conditions gave similar results.

An additional experiment examined citrate utilization of the two strains $\mathrm{Cm}$ 6-1 and ATCC 35586 during growth in APT broth with 22 or $30 \mathrm{mM}$ citrate. Bacterial concentrations increased, irrespectively of initial citrate concentration, from log 6.1 CFU/mL (Cm 6-1) or $\log 6.3 \mathrm{CFU} / \mathrm{mL}$ (ATCC 35586) to $\log 8.7 \mathrm{CFU} / \mathrm{mL}$ (Cm 6-1) or $\log 9.1 \mathrm{CFU} / \mathrm{mL}$ (ATCC 35586) after 9 days of incubation at $25^{\circ} \mathrm{C}$. The medium with the lowest initial concentration of citrate (22 mM) contained either 18.7 (ATCC 35586; an average of three replica cultures) or 19.5 (Cm 6-1; an average of four replica cultures) $\mathrm{mM}$ citrate at end of incubation. One ATCC 35586 sample that only contained $12 \mathrm{mM}$ was noted as an outlier and was not included in the average. Similarly, the medium with the highest initial concentration of citrate $(30 \mathrm{mM})$ contained $28.25 \mathrm{mM}$ at the end of incubation irrespective of strain (average of four replica cultures in each case, see Table S2 for details). Taking into consideration that the analysis had a relative standard deviation of $3 \%$, the results indicate that the two strains did not—or only to a limited extent—utilize citrate when present in relatively high amounts. Production of short-chain fatty acids was also examined in this experiment. Both strains showed limited production of acetic acid: $1.8 \mathrm{mM}$ or $1.2 \mathrm{mM}$ for the 3Ba-II-6 strain and 2.5 or $1.5 \mathrm{mM}$ for the ATCC 35586 strain in APT broth with 22 or $30 \mathrm{mM}$ citrate, respectively. Production of formic acid depended on strain: 11.1 or $9.1 \mathrm{mM}$ for the 3Ba-II-6 strain and 2.4 or $0.6 \mathrm{mM}$ for the ATCC 35586 strain in APT broth with 22 or $30 \mathrm{mM}$ citrate, respectively. These values were calculated by subtraction of concentrations found in sterile media: $5.5 \mathrm{mM}$ or $7.6 \mathrm{mM}$ acetic acid and 2.5 or $4.7 \mathrm{mM}$ formic acid in APT broth with 22 or $30 \mathrm{mM}$ citrate, respectively.

Several genes, identified by genome annotations, were associated with two different pathways for citrate metabolism in C. maltaromaticum (Figures 1, 2, 3 and S1). Pathway 1 constitutes the typical LAB citrate metabolism pathway and includes oxaloacetate as an intermediate, and pathway 2 includes TCA compounds as intermediates ( Figures 13). All examined strains encoded the pathway 2 genes whereas only two strains encoded the pathway 1 genes (Table 1). A screening of whole-genome sequences of 14 additional C. maltaromaticum strains showed the presence of genes associated with pathway 1 in three other strains and the presence of genes associated with pathway 2 in all 14 strains (Figure S1). SNP analysis indicated that the $C$. maltaromaticum strains possessing pathway 1 genes are not necessarily closely related (Figure S1). 


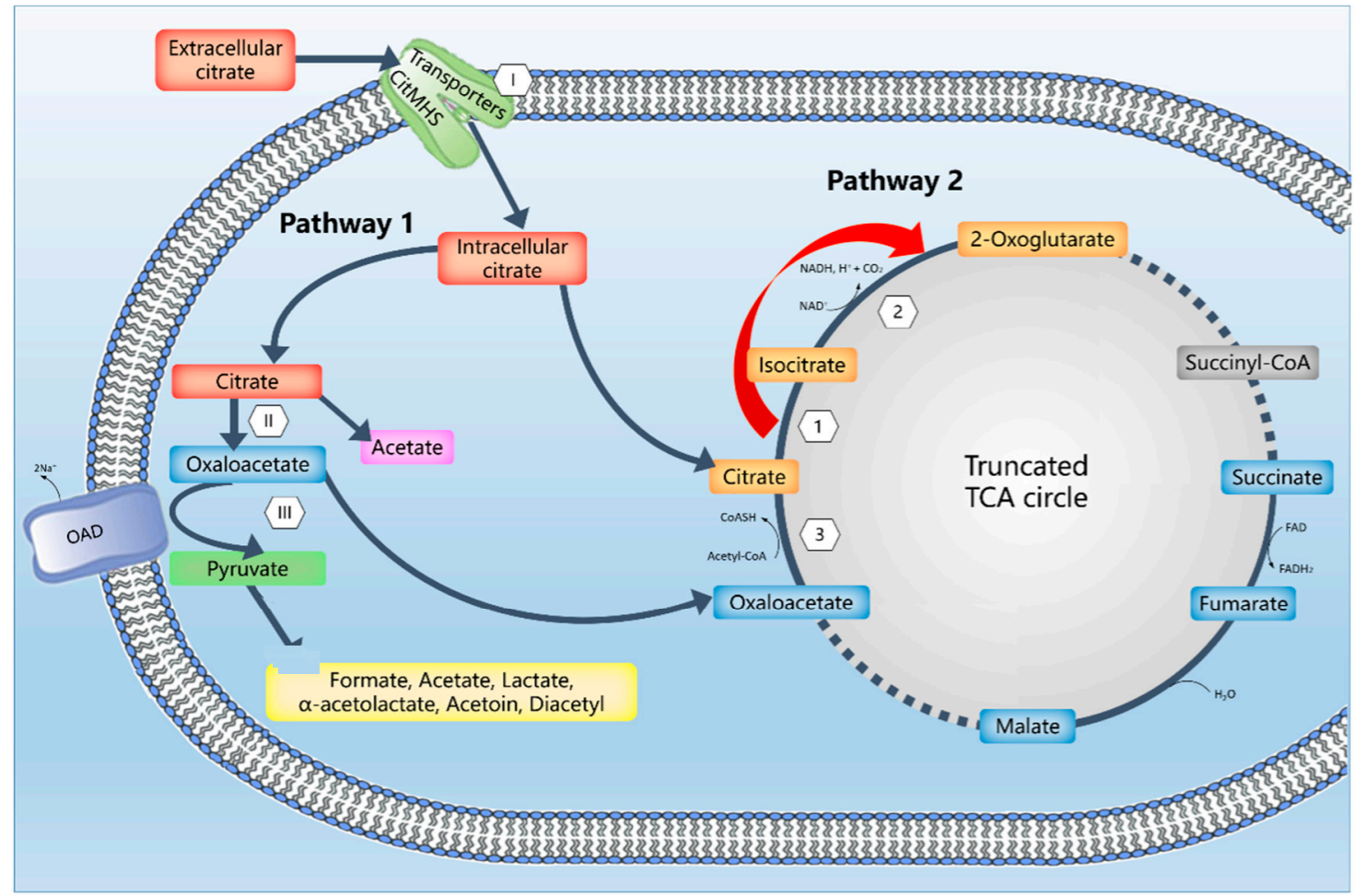

Figure 3. The prediction of citrate metabolism pathways in the C. maltaromaticum Cm 6-1 strain (see Table 1, Figures 1 and 2 for a complete list of genes). Pathway 1 constitutes the typical citrate catabolism pathway with oxaloacetate as an intermediate. I: Citrate MHS transporter; II: citrate lyase complex; III: oxaloacetate decarboxylase complex. Pathway 2 includes isocitrate and $\alpha$-ketoglutarate as intermediates. 1: Aconitate hydratase; 2 : isocitrate dehydrogenase, 3: citrate synthase. A potentially associated citrate transporter is not shown in the figure.

None of these pathways were detected in five strains of Carnobacterium divergens or one strain each for Carnobacterium funditum and Carnobacterium viridans, whereas pathway 1 was observed in one strain of Carnobacterium pleistocenium. The presence of pathway 1 genes in only some $C$. maltaromaticum strains indicate that their presence could either be due to a transfer event from another species or they have been lost from several lineages of $C$. maltaromaticum. In relation to the first possibility, we have previously discussed the capability of genome expansion in C. maltaromaticum compared to other Carnobacterium spp. [28]. BLAST analyses, as well as the alignment and construction of phylogenetic trees of predicted protein domains of $C$. maltaromaticum $\mathrm{Cm}$ 6-1 pathway 1 gene products, indicated that the most similar gene sequences were generally found in the related Isobaculum melis, with Vagococcus salmoninarum possessing the second-closest related set of genes (results not shown). It will be of interest to conduct further studies on whether citrate pathway 1 genes are localized on plasmids in order to evaluate the stability of their presence in individual strains.

The overall organization of the pathway 1 gene cluster is similar in the four strains $\mathrm{Cm}$ 4-1, Cm 6-1, JIP 2891, and 10040100629 (Figures 1 and S2A). Following the citM-CDEFGT cluster nomenclature [29] and with the Cm 6-1 sequence as an example, the locus tag 3134 encodes a GntR family transcriptional regulator $\mathrm{CitO}$ that may regulate the activity of the cit promoters [30,31]. Locus tags 3135 and 3136 are hypothetical proteins probably associated with the active citrate lyase complex and similar to CitG and CitT [29]. Locus tag 3141 was predicted as a CitMHS transporter for citrate/H+ (CitM), a metal-citrate complex protein that transports the citrate ${ }^{2-}-\mathrm{Mg}^{2+}$ complex $[29,32,33]$. Locus tags 3142 , 3143, and 3144 encoded CitDEF: citrate lyase alpha, beta, and gamma chains, respectively. Locus tag 3145 encoded CitC: citrate lyase ligase. The locus tags 3137 and 3140 encoded oxaloacetate decarboxylase (OAD) beta and alpha chains, respectively. 
In the L. lactis biovar. diacetylactis CRL264 strain, citrate transport, and metabolism are composed of the chromosomal citM(4citO)-I-CDEFXG cluster [34]. However, in the present study, we only observed the cluster of citM(H)-CDEFGT(X) without citI gene.

The gene products associated with locus tags 3138 and 3139 are related to transmembrane function; region and transmembrane helices were predicted for the 3139 gene product by use of the TMHMM server. These proteins may be associated with the functionality of the OAD-beta chain, and the latter was also predicted to contain transmembrane helices. Transmembrane OAD has previously been identified in LAB and has been associated with the type II citrate pathway in E. faecalis [12,35].

Soluble OAD are classified into three groups (EC 1.1.1.38, EC1.1.1.39, EC1.1.1.40) based on the malic enzymes (MEs). Notably, the soluble OAD (EC1.1.1.40) was identified in the Cm 6-1 strain (locus tag 1547), indicating an additional potential ability to convert oxaloacetate to pyruvate [36,37].

Pathway 2 includes the conversion of citrate into isocitrate and $\alpha$-ketoglutarate by a truncated tricarboxylic acid (TCA) cycle containing the genes encoding aconitate hydratase and isocitrate dehydrogenase but lacking the genes encoding the reactions from $\alpha$-ketoglutarate to succinate (Figures 2, 3 and S2B). This pathway is described for other LAB [38-40]. The pathway 2 genes clustered together with a gene encoding citrate synthase that synthesizes citrate from oxaloacetate and acetyl-CoA (Figures 2, 3 and S2B). Thus, oxaloacetate or citrate, perhaps imported by a presumptive transporter (L-malate or Citrate $/ \mathrm{H}^{+}$symporter, $\mathrm{CimH}$, locus tag 1548 in $\mathrm{Cm}$ 6-1 sequence) encoded by a gene present in all six strains (Table 1) are presumable substrates.

The experimental conditions employed in the initial phenotypic screening of Carnobacterium maltaromaticum citrate degradation did not induce pathway 1 , as indicated by the negative result for strain $\mathrm{Cm}$ 4-1 that contains the genes for pathway 1 but showed a negative phenotype (Table 1). Thus, the observed phenotype on citrate utilizing media appeared not to be associated with the presence of pathway 1 genes.

Furthermore, APT broth with $1 \%$ glucose and 22 or $30 \mathrm{mM}$ citrate did not appear to support citrate utilization by C. maltaromaticum ATCC 35586 (with genes encoding pathway 2) or Cm 6-1 (with genes encoding pathways 1 and 2) or to affect the production of short-chain fatty acids to any significant extent. The presence of glucose may suppress the conversion of citrate in E. faecalis but not in L. lactis, Lacticaseibacillus casei, or L. plantarum [3,41,42]. As the medium employed in the initial phenotypical screeningwhich showed some citrate utilization as described above-also contains glucose, it is currently not clear what effect glucose might have on C. maltaromaticum citrate catabolism. Among other carbohydrates, galactose may exert an enhancing effect for citrate metabolism in E. faecalis, L. casei, and L. plantarum. Suppression of citrate metabolism by lactose was not observed in L. casei, L. plantarum, or Leuconostoc mesenteroides [3,43] and depended on the medium in E. faecalis [44].

$\mathrm{pH}$ also affects citrate catabolism, with the highest activity observed between $\mathrm{pH} 5.5$ and 6.0 in Lc. lactis and Leuconostoc spp. [45], whereas other studies show that low $\mathrm{pH}$ values increased activity in Lc. lactis, L. casei, and L. plantarum $[3,46]$. Citrate may also be an inducer, as shown for E. faecalis and L. mesenteroides [31,47-49], although this compound does not appear as a satisfactory condition for C. maltaromaticum during growth in APT broth with citrate.

Succinate is a product of the reductive TCA cycle for some LAB, such as strains belonging to L. pentosus and L. plantarum [50,51]. Implicated enzymes include malate dehydrogenase, fumarase, and fumarate reductase [50,51]. Using RAST, we found a potential fumarate hydratase gene (=fumarase) (locus tag 2880 in the Cm 6-1 sequence) and a gene encoding a redox protein related to succinate dehydrogenase/fumarate reductase (locus tag 3513 in the Cm 6-1 sequence) in all genomes for strains included in Table 1, whereas there was no evidence for a malate dehydrogenase gene. This potential lack of one of the genes necessary for encoding such a pathway agrees with the lack of reports on the production of succinate by C. maltaromaticum. 
Pyruvate serves as a substrate for C. maltaromaticum for the production of lactic and acetic acid, formic acid, $\mathrm{CO}_{2}$, acetoin, diacetyl, and 2-3-butanediol [5]. Oxaloacetate and pyruvate may be converted into $\alpha$-ketoglutarate by the aspartate aminotransferase and alanine aminotransferase enzymes, respectively [49]. These two enzymes are widely detected in various LABs. Isocitrate dehydrogenase in pathway 2 also converts isocitrate into $\alpha$-ketoglutarate (Figure 3). The $\alpha$-ketoglutarate compound may then undergo a transamination reaction with leucine, resulting in the formation of 3-methyl butanal and 3-methyl butanol. These two compounds are also produced by C. maltaromaticum [49,52-54]. The overall effects of citrate on pyruvate and $\alpha$-ketoglutarate catabolism in C. maltaromaticum are not known. It will be of interest to examine this further, especially with regard to the synthesis of the flavor compounds diacetyl and 3-methyl-butanal.

In conclusion, this study shows that some strains of C. maltaromaticum appear to encode two different pathways for metabolizing citrate. To our knowledge, this is the first genetic analysis on potential citrate metabolism pathways for the Carnobacterium genus. Currently, the conditions that activate the citrate pathways are not known and further studies are required to illuminate them. As this species has potential as an adjunct culture in soft cheese products, it would also be of interest to investigate whether citrate catabolism in C. maltaromaticum by pathway 1 and/or pathway 2 may result in the production of flavor compounds under conditions prevailing in such products. We are currently researching that direction by examining the external regulation of citrate catabolism in Carnobacterium maltaromaticum.

Supplementary Materials: The following are available online at https:/ / www.mdpi.com/article/10 $.3390 /$ microorganisms $9102169 /$ s1, Table S1. Compilation of genes related to citrate metabolism in Carnobacterium maltaromaticum 3Ba-6-II. Table S2. The citrate utilization of the two Carnobacterium maltaromaticum strains Cm 6-1 and ATCC 5586. Figure S1. Comparison of SNP cladogram with the absence or presence of citrate pathway 1 and 2 genes in published genomes of $C$. maltaromaticum as well as other Carnobacterium spp. The filled squares indicate the confirmed presence while empty squares indicate the absence of pathway genes. The assembly accession includes IDs/numbers from NCBI bioproject, GenBank accession numbers, and RAST annotation server IDs. Figure S2. (A) Organization of pathway 1 gene cluster in the strains Cm 4-1, Cm 6-1, JIP 2891, and 10040100629. Mobile elements were situated next to the gene encoding the citrate lyase ligase in the 10040100629 strain. (B) Organization of truncated pathway 2 gene cluster in the nine strains $\mathrm{Cm} 5-1, \mathrm{Cm} \mathrm{3-1,} \mathrm{Cm}$ 6-1, Cm 1-2, Cm 4-1, JIP 2891, 10040100629, LMA28, and ATCC 35586.

Author Contributions: Conceptualization, H.L., F.B., F.K.V. and J.J.L.; methodology, H.L. and J.J.L.; software, H.L., N.E.R. and F.B.; validation, H.L., N.E.R., F.B., A.-M.R.-J. and J.J.L.; formal analysis, H.L., F.B. and J.J.L.; investigation, H.L., and J.J.L.; resources, H.L, N.E.R., F.B., A.-M.R.-J., F.K.V. and J.J.L.; data curation, H.L.; writing—original draft preparation, H.L. and J.J.L.; writing-review and editing, H.L., N.E.R., F.B., A.-M.R.-J., F.K.V. and J.J.L.; visualization, H.L.; supervision, J.J.L.; project administration, J.J.L.; funding acquisition, H.L., F.B., A.-M.R.-J., F.K.V. and J.J.L. All authors have read and agreed to the published version of the manuscript.

Funding: This work was supported by a young scholar grant to Heng Li from Soochow University (GJ12100120).

Institutional Review Board Statement: Not applicable.

Informed Consent Statement: Not applicable.

Data Availability Statement: The genome sequences of Cm 4-1, Cm 6-1, Cm 1-2, Cm 3-1, and Cm 5-1 strains (BioProject ID: PRJEB40278) and of JIP 2891 and 10040100629 strains (BioProject ID: PRJEB40429) were uploaded to GenBank. The Carnobacterium divergens Cd 1-1 sequence was from the RAST annotation server (job ID \#692064). Sequences of ATCC 35586, LMA 28, and the remaining strains were downloaded from GenBank. Accession numbers are listed in Figure S1.

Acknowledgments: We thank Vi Phuong Thi Nguyen and Gitte Petersen for their excellent technical support regarding the phenotypic tests. 
Conflicts of Interest: The authors declare no conflict of interest. The funders had no role in the design of the study; in the collection, analyses, or interpretation of data; in the writing of the manuscript, or in the decision to publish the results.

\section{References}

1. Hugenholtz, J. Citrate metabolism in lactic acid bacteria. FEMS Microbiol. Rev. 1993, 12, 165-178. [CrossRef]

2. Morea, M.; Baruzzi, F.; Cocconcelli, P. Molecular and physiological characterization of dominant bacterial populations in traditional Mozzarella cheese processing. J. Appl. Microbiol. 1999, 87, 574-582. [CrossRef]

3. Palles, T.; Beresford, T.; Condon, S.; Cogan, T.M. Citrate metabolism in Lactobacillus casei and Lactobacillus plantarum. J. Appl. Microbiol. 1998, 85, 147-154. [CrossRef]

4. Bintsis, T. Lactic acid Bacteria as starter cultures: An update in their metabolism and genetics. AIMS Microbiol. 2018, 4, 665-684. [CrossRef] [PubMed]

5. Leisner, J.J.; Laursen, B.G.; Prévost, H.; Drider, D.; Dalgaard, P. Carnobacterium: Positive and negative effects in the environment and in foods. FEMS Microbiol. Rev. 2007, 31, 592-613. [CrossRef]

6. Leisner, J.J.; Hansen, M.A.; Larsen, M.H.; Hansen, L.; Ingmer, H.; Sørensen, S.J. The genome sequence of the lactic acid bacterium, Carnobacterium maltaromaticum ATCC 35586 encodes potential virulence factors. Int. J. Food Microbiol. 2012, 152, 107-115. [CrossRef]

7. Toranzo, A.; Romalde, J.; Nunez, S.; Figueras Huerta, A.; Barja, J. An epizootic in farmed, market-sized rainbow trout in Spain caused by a strain of Carnobactenum piscicola of unusual virulence. Dis. Aquat. Org. 1993, 121, 6107-6108. [CrossRef]

8. Roh, H.; Kim, B.S.; Lee, M.K.; Park, C.-I.; Kim, D.-H. Genome-wide comparison of Carnobacterium maltaromaticum derived from diseased fish harbouring important virulence-related genes. J. Fish Dis. 2020, 43, 1029-1037. [CrossRef]

9. Afzal, M.I.; Ariceaga, C.C.G.; Lhomme, E.; Ali, N.K.; Payot, S.; Burgain, J.; Gaiani, C.; Borges, F.; Revol-Junelles, A.-M.; Delaunay, S.; et al. Characterization of Carnobacterium maltaromaticum LMA 28 for its positive technological role in soft cheese making. Food Microbiol. 2013, 36, 223-230. [CrossRef] [PubMed]

10. Østlie, H.M.; Treimo, J.; Narvhus, J.A. Effect of temperature on growth and metabolism of probiotic bacteria in milk. Int. Dairy J. 2005, 15, 989-997. [CrossRef]

11. Singh, T.; Drake, M.A.; Cadwallader, K.R. Flavor of Cheddar cheese: A chemical and sensory perspective. Compr. Rev. Food Sci. Food Saf. 2003, 2, 166-189. [CrossRef]

12. García-Quintáns, N.; Blancato, V.S.; Repizo, G.D.; Magni, C.; López, P. Citrate metabolism and aroma compound production in lactic acid bacteria. In Molecular Aspects of Lactic Acid Bacteria for Traditional and New Applications; Research Signpost: Trivandrum, India, 2008.

13. Leisner, J.J.; Vogensen, F.K.; Kollmann, J.; Aideh, B.; Vandamme, P.; Vancanneyt, M.; Ingmer, H. $\alpha$-Chitinase activity among lactic acid bacteria. Syst. Appl. Microbiol. 2008, 31, 151-156. [CrossRef]

14. Kempler, G.M.; McKay, L.L. Improved medium for detection of citrate-fermenting Streptococcus lactis subsp. diacetylactis. Appl. Environ. Microbiol. 1980, 39, 926-927. [CrossRef]

15. Smart, K.F.; Aggio, R.B.M.; Van Houtte, J.R.; Villas-Bôas, S.G. Analytical platform for metabolome analysis of microbial cells using methyl chloroformate derivatization followed by gas chromatography-mass spectrometry. Nat. Protoc. 2010, 5, 1709-1729. [CrossRef]

16. Johnsen, L.G.; Skou, P.B.; Khakimov, B.; Bro, R. Gas chromatography-mass spectrometry data processing made easy. J. Chromatogr. A 2017, 1503, 57-64. [CrossRef] [PubMed]

17. Aziz, R.K.; Bartels, D.; Best, A.A.; DeJongh, M.; Disz, T.; Edwards, R.A.; Formsma, K.; Gerdes, S.; Glass, E.M.; Kubal, M. The RAST Server: Rapid annotations using subsystems technology. BMC Genom. 2008, 9, 75-content. [CrossRef]

18. Overbeek, R.; Olson, R.; Pusch, G.D.; Olsen, G.J.; Davis, J.J.; Disz, T.; Edwards, R.A.; Gerdes, S.; Parrello, B.; Shukla, M.; et al. The SEED and the Rapid Annotation of microbial genomes using Subsystems Technology (RAST). Nucleic Acids Res. 2014, 42, 206-214. [CrossRef] [PubMed]

19. Brettin, T.; Davis, J.J.; Disz, T.; Edwards, R.A.; Gerdes, S.; Olsen, G.J.; Olson, R.; Overbeek, R.; Parrello, B.; Pusch, G.D.; et al. RASTtk: A modular and extensible implementation of the RAST algorithm for building custom annotation pipelines and annotating batches of genomes. Sci. Rep. 2015, 5, 8365. [CrossRef]

20. Letunic, I.; Bork, P. Interactive tree of life (iTOL) v3: An online tool for the display and annotation of phylogenetic and other trees. Nucleic Acids Res. 2016, 44, 242-245. [CrossRef] [PubMed]

21. Schultz, J.; Copley, R.R.; Doerks, T.; Ponting, C.P.; Bork, P. SMART: A web-based tool for the study of genetically mobile domains. Nucleic Acids Res. 2000, 28, 231-234. [CrossRef] [PubMed]

22. El-Gebali, S.; Mistry, J.; Bateman, A.; Eddy, S.R.; Luciani, A.; Potter, S.C.; Qureshi, M.; Richardson, L.J.; Salazar, G.A.; Smart, A. The Pfam protein families database in 2019. Nucleic Acids Res. 2019, 47, 427-432. [CrossRef]

23. Consortium, U. UniProt: A hub for protein information. Nucleic Acids Res. 2015, 43, 204-212. [CrossRef] [PubMed]

24. Kanehisa, M. The KEGG Database Novartis Foundation Symposium. 2002, 247, 91-100.

25. Vallenet, D.; Belda, E.; Calteau, A.; Cruveiller, S.; Engelen, S.; Lajus, A.; Le Fèvre, F.; Longin, C.; Mornico, D.; Roche, D.; et al. MicroScope-An integrated microbial resource for the curation and comparative analysis of genomic and metabolic data. Nucleic Acids Res. 2013, 41, 636-647. [CrossRef] 
26. Petkau, A.; Stuart-Edwards, M.; Stothard, P.; Van Domselaar, G. Interactive microbial genome visualization with GView. Bioinformatics 2010, 26, 3125-3126. [CrossRef] [PubMed]

27. Krogh, A.; Larsson, B.; Von Heijne, G.; Sonnhammer, E.L. Predicting transmembrane protein topology with a hidden Markov model: Application to complete genomes. J. Mol. Biol. 2001, 305, 567-580. [CrossRef] [PubMed]

28. Iskandar, C.F.; Borges, F.; Taminiau, B.; Daube, G.; Zagorec, M.; Remenant, B.; Leisner, J.J.; Hansen, M.A.; Sørensen, S.J.; Mangavel, C.; et al. Comparative genomic analysis reveals ecological differentiation in the genus Carnobacterium. Front. Microbiol. 2017, 8, 357. [CrossRef]

29. Eisenbach, L.; Geissler, A.J.; Ehrmann, M.A.; Vogel, R.F. Comparative genomics of Lactobacillus sakei supports the development of starter strain combinations. Microbiol. Res. 2019, 221, 1-9. [CrossRef]

30. Blancato, V.S.; Pagliai, F.A.; Magni, C.; Gonzalez, C.F.; Lorca, G.L. Functional analysis of the citrate activator CitO from Enterococcus faecalis implicates a divalent metal in ligand binding. Front. Microbiol. 2016, 7, 101. [CrossRef]

31. Blancato, V.S.; Repizo, G.D.; Suárez, C.A.; Magni, C. Transcriptional regulation of the citrate gene cluster of Enterococcus faecalis Involves the GntR family transcriptional activator CitO. J. Bacteriol. 2008, 190, 7419-7430. [CrossRef]

32. Lensbouer, J.J.; Doyle, R.P. Secondary transport of metal-citrate complexes: The CitMHS family. Crit. Rev. Biochem. Mol. Biol. 2010, 45, 453-462. [CrossRef]

33. Blancato, V.S.; Magni, C.; Lolkema, J.S. Functional characterization and $\mathrm{Me}^{2+}$ ion specificity of a Ca ${ }^{2+}$-citrate transporter from Enterococcus faecalis. FEBS J. 2006, 273, 5121-5130. [CrossRef] [PubMed]

34. Manno, M.T.; Zuljan, F.; Alarcón, S.; Esteban, L.; Blancato, V.; Espariz, M.; Magni, C. Genetic and phenotypic features defining industrial relevant Lactococcus lactis, L. cremoris and L. lactis biovar. diacetylactis strains. J. Biotechnol. 2018, 282, 25-31. [CrossRef] [PubMed]

35. Repizo, G.D.; Blancato, V.S.; Mortera, P.; Lolkema, J.S.; Magni, C. Biochemical and genetic characterization of the Enterococcus faecalis oxaloacetate decarboxylase complex. Appl. Environ. Microbiol. 2013, 79, 2882-2890. [CrossRef] [PubMed]

36. Sender, P.D.; Martín, M.G.; Peirú, S.; Magni, C. Characterization of an oxaloacetate decarboxylase that belongs to the malic enzyme family. FEBS Lett. 2004, 570, 217-222. [CrossRef] [PubMed]

37. Espariz, M.; Repizo, G.; Blancato, V.; Mortera, P.; Alarcón, S.; Magni, C. Identification of malic and soluble oxaloacetate decarboxylase enzymes in Enterococcus faecalis. FEBS J. 2011, 278, 2140-2151. [CrossRef] [PubMed]

38. Morishita, T.; Yajima, M. Incomplete operation of biosynthetic and bioenergetic functions of the citric acid cycle in multiple auxotrophic lactobacilli. Biosci. Biotechnol. Biochem. 1995, 59, 251-255. [CrossRef]

39. Lapujade, P.; Cocaign-Bousquet, M.; Loubiere, P. Glutamate biosynthesis in Lactococcus lactis subsp. lactis NCDO 2118. Appl. Environ. Microbiol. 1998, 64, 2485-2489. [CrossRef]

40. Wang, H.; Baldwin, K.A.; O'Sullivan, D.J.; McKay, L.L. Identification of a gene cluster encoding Krebs cycle oxidative enzymes linked to the pyruvate carboxylase gene in Lactococcus lactis ssp. lactis C2. J. Dairy Sci. 2000, 83, 1912-1918. [CrossRef]

41. Rea, M.C.; Cogan, T.M. Glucose prevents citrate metabolism by enterococci. Int. J. Food Microbiol. 2003, 88, 201-206. [CrossRef]

42. Pudlik, A.M.; Lolkema, J.S. Citrate uptake in exchange with Intermediates in the citrate metabolic pathway in Lactococcus lactis IL1403. J. Bacteriol. 2011, 193, 706-714. [CrossRef]

43. Schmitt, P.; Diviès, C.; Merlot, C. Utilization of citrate by Leuconostoc mesenteroides subsp. cremoris in continuous culture. Biotechnol. Lett. 1990, 12, 127-130. [CrossRef]

44. Sarantinopoulos, P.; Kalantzopoulos, G.; Tsakalidou, E. Citrate metabolism by Enterococcus faecalis FAIR-E 229. Appl. Environ. Microbiol. 2001, 67, 5482-5487. [CrossRef] [PubMed]

45. Starrenburg, M.J.; Hugenholtz, J. Citrate fermentation by Lactococcus and Leuconostoc spp. Appl. Environ. Microbiol. 1991, 57, 3535-3540. [CrossRef]

46. García-Quintáns, N.; Magni, C.; de Mendoza, D.; López, P. The citrate transport system of Lactococcus lactis subsp. lactis biovar diacetylactis is induced by acid stress. Appl. Environ. Microbiol. 1998, 64, 850-857. [CrossRef]

47. Marty-Teysset, C.; Posthuma, C.; Lolkema, J.S.; Schmitt, P.; Divies, C.; Konings, W.N. Proton motive force generation by citrolactic fermentation in Leuconostoc mesenteroides. J. Bacteriol. 1996, 178, 2178-2185. [CrossRef] [PubMed]

48. Martino, G.P.; Quintana, I.M.; Espariz, M.; Blancato, V.S.; Nizo, G.G.; Esteban, L.; Magni, C. Draft Genome sequences of four Enterococcus faecium strains isolated from Argentine cheese. Genome Announc. 2016, 4, 1515-1576. [CrossRef]

49. D’Angelo, M.; Martino, G.P.; Blancato, V.S.; Espariz, M.; Hartke, A.; Sauvageot, N.; Benachour, A.; Alarcón, S.H.; Magni, C. Diversity of volatile organic compound production from leucine and citrate in Enterococcus faecium. Appl. Microbiol. Biotechnol. 2020, 104, 1175-1186. [CrossRef]

50. Cselovszky, J.; Wolf, G.; Hammes, W.P. Production of formate, acetate, and succinate by anaerobic fermentation of Lactobacillus pentosus in the presence of citrate. Appl. Microbiol. Biotechnol. 1992, 37, 94-97. [CrossRef]

51. Dudley, E.G.; Steele, J.L. Succinate production and citrate catabolism by Cheddar cheese nonstarter lactobacilli. J. Appl. Microbiol. 2005, 98, 14-23. [CrossRef] 
52. Larrouture-Thiveyrat, C.; Montel, M.-C. Effects of environmental factors on leucine catabolism by Carnobacterium piscicola. Int. J. Food Microbiol. 2003, 81, 177-184. [CrossRef]

53. Afzal, M.I.; Delaunay, S.; Paris, C.; Borges, F.; Revol-Junelles, A.-M.; Cailliez-Grimal, C. Identification of metabolic pathways involved in the biosynthesis of flavor compound 3-methylbutanal from leucine catabolism by Carnobacterium maltaromaticum LMA 28. Int. J. Food Microbiol. 2012, 157, 332-339. [CrossRef] [PubMed]

54. Afzal, M.I.; Boulahya, K.-A.; Paris, C.; Delaunay, S.; Cailliez-Grimal, C. Effect of oxygen on the biosynthesis of flavor compound 3-methylbutanal from leucine catabolism during batch culture in Carnobacterium maltaromaticum LMA 28. J. Dairy Sci. 2013, 96, 352-359. [CrossRef] [PubMed] 